\title{
Variable Tidal Volumes Improve Lung Protective Ventilation Strategies in Experimental Lung Injury
}

\author{
Peter M. Spieth', Alysson R. Carvalho', Paolo Pelosi², Catharina Hoehn', Christoph Meissner', Michael Kasper ${ }^{3}$, \\ Matthias Hübler ${ }^{1}$, Matthias von Neindorff ${ }^{1}$, Constanze Dassow ${ }^{4}$, Martina Barrenschee ${ }^{4}$, Stefan Uhlig ${ }^{4}$, \\ Thea Koch', and Marcelo Gama de Abreu' ${ }^{1}$ \\ ${ }^{1}$ Department of Anesthesiology and Intensive Care Therapy, University Hospital Dresden, Dresden, Germany; ${ }^{2}$ Department of Ambient, Health and \\ Safety, University of Insubria, Varese, Italy; ${ }^{3}$ Institute of Anatomy, University of Dresden, Dresden, Germany; ${ }^{4}$ Institute of Pharmacology and \\ Toxicology, University of Aachen, Aachen, Germany
}

\begin{abstract}
Rationale: Noisy ventilation with variable $\mathrm{V}_{\mathrm{T}}$ may improve respiratory function in acute lung injury.

Objectives: To determine the impact of noisy ventilation on respiratory function and its biological effects on lung parenchyma compared with conventional protective mechanical ventilation strategies.

Methods: In a porcine surfactant depletion model of lung injury, we randomly combined noisy ventilation with the ARDS Network protocol or the open lung approach ( $\mathbf{n}=\mathbf{9}$ per group).

Measurements and Main Results: Respiratory mechanics, gas exchange, and distribution of pulmonary blood flow were measured at intervals over a 6-hour period. Postmortem, lung tissue was analyzed to determine histological damage, mechanical stress, and inflammation. We found that, at comparable minute ventilation, noisy ventilation (1) improved arterial oxygenation and reduced mean inspiratory peak airway pressure and elastance of the respiratory system compared with the ARDS Network protocol and the open lung approach, (2) redistributed pulmonary blood flow to caudal zones compared with the ARDS Network protocol and to peripheral ones compared with the open lung approach, (3) reduced histological damage in comparison to both protective ventilation strategies, and (4) did not increase lung inflammation or mechanical stress.

Conclusions: Noisy ventilation with variable $\mathrm{V}_{\mathrm{T}}$ and fixed respiratory frequency improves respiratory function and reduces histological damage compared with standard protective ventilation strategies.
\end{abstract}

Keywords: mechanical ventilation; acute lung injury; experimental model; variable ventilation; inflammation

Clinical studies have demonstrated that mortality associated with acute lung injury (ALI) and acute respiratory distress syndrome (ARDS) may be reduced with ventilation strategies aimed at avoiding excessive lung stretching $(1,2)$. Two approaches of lung-protective mechanical ventilation are used in clinical practice. The first approach, suggested by the ARDS Network (ARDSnet), is aimed at minimizing lung strain while maintaining minimal acceptable gas exchange $(2,3)$. These aims are achieved by using (1) VT as low as 4 to $6 \mathrm{ml} / \mathrm{kg}$ (ideal body weight) and (2) combinations of positive end-expiratory pressures (PEEP) and $\mathrm{FI}_{\mathrm{O}_{2}}$ to keep inspiratory plateau pressures $<30 \mathrm{~cm} \mathrm{H}_{2} \mathrm{O}$ and to achieve arterial oxygen saturation in the range of 88 to $95 \%$. The second one, known as open lung approach (OLA), also uses low VT. In the OLA, recruitment

(Received in original form June 27, 2008; accepted in final form January 14, 2009) Supported by grant AB 135/3-3 from the German Research Council (D.F.G.).

Correspondence and requests for reprints should be addressed to Dr. Marcelo Gama de Abreu, Clinic of Anesthesiology and Intensive Care Therapy, University Hospital Dresden, Fetscherstrasse 74, 01307 Dresden, Germany. E-mail: mgabreu@ uniklinikum-dresden.de

This article has an online supplement, which is accessible from this issue's table of contents at www.atsjournals.org

Am J Respir Crit Care Med Vol 179. pp 684-693, 2009

Originally Published in Press as DOI: 10.1164/rccm.200806-975OC on January 16, 2009

Internet address: www.atsjournals.org

\section{AT A GLANCE COMMENTARY}

Scientific Knowledge on the Subject

In acute lung injury, variation of $\mathrm{V}_{\mathrm{T}}$ and respiratory frequency has been proposed to improve respiratory function, but their effects on lung histological damage, mechanical stress, and inflammation are only poorly defined.

\section{What This Study Adds to the Field}

In acute lung injury, variation of $\mathrm{V}_{\mathrm{T}}$ in combination with different protective ventilation strategies improves respiratory function and reduces histological damage while not increasing lung mechanical stress or inflammation.

maneuvers (RM) are used to open up the lungs and PEEP is titrated to optimize physiological endpoints like gas exchange (4) or respiratory mechanics (5).

However, both protective ventilation strategies have a monotonic breathing pattern (i.e., no variation in VT and/or respiratory frequency [f]). Such a pattern is significantly different from that observed in spontaneously breathing healthy subjects, showing intrinsic variability (6). Different authors demonstrated that variation of the respiratory pattern during controlled mechanical ventilation may be useful to improve the pulmonary function (7-13), but this claim has been challenged (14). Suki and colleagues (7) suggested that the lungs may work as a stochastic resonance system, where the variability of input parameters (e.g., end-inspiratory pressure) may increase the surface area for gas exchange in the lungs, resulting in improved output (e.g., oxygenation). Brewster and colleagues (15) suggested that variability may be more useful when applied at lungs with convex shaped pressure-volume curves, indicating higher potential for recruitment. In oleic acid-induced ALI, Boker and colleagues (13) showed that IL-8 concentrations in tracheal aspirates could be reduced by variable ventilation combined to the ARDSnet protocol, but histological damage has not been assessed. Furthermore, the combination of variable ventilation with the open lung approach was not tested.

In the present study, we evaluated the use of variable $\mathrm{VT}_{\mathrm{T}}$ (noisy ventilation) at fixed $\mathrm{f}$ combined with ARDSnet and OLA in a surfactant-depletion model of acute lung injury (ALI). Because alveolar recruitment was postulated as the most important mechanism of noisy ventilation (9), we hypothesized that the combination of noisy ventilation with ARDSnet protocol would improve functional parameters of the respiratory system, whereas such beneficial effects would be less evident in comparison to OLA. Furthermore, we investigated the effects of noisy ventilation on lung mechanical stress and inflammation. Part of the data presented in the current work has been published in abstract form (16). 


\section{METHODS}

\section{Experimental Protocol}

After approval by the local Animal Care Committee, 36 pigs (23.8$37.0 \mathrm{~kg}$ ) were anesthetized, mechanically ventilated, and instrumented. After induction of ALI, animals were randomly assigned to the ARDSnet protocol or to OLA with or without noisy ventilation ( $n=9$ /group). Lung mechanics, gas exchange, hemodynamics, and distribution of pulmonary blood flow (PBF) were determined at intervals. After 6 hours, animals were killed, and the lungs were extracted for postmortem analysis (see below).

\section{Ventilator Settings}

Mechanical ventilation was performed in volume controlled mode using the EVITA XL 4 Lab (Dräger Medical, Lübeck, Germany). Ventilator settings are summarized in Table 1.

\section{ALI}

ALI was induced by surfactant depletion (17) until $\mathrm{PA}_{\mathrm{O}_{2}} / \mathrm{FI}_{\mathrm{O}_{2}}<$ $200 \mathrm{~mm} \mathrm{Hg}$ for 30 minutes.

\section{PEEP Adjustment}

In ARDSnet and ARDSnet+noisy groups, PEEP was set at $12 \mathrm{~cm} \mathrm{H}_{2} \mathrm{O}$ and $\mathrm{FI}_{\mathrm{O}_{2}}$ at 0.7 (2). In OLA and OLA+ noisy groups, a RM $\left(40 \mathrm{~cm} \mathrm{H}_{2} \mathrm{O}\right.$ for $30 \mathrm{~s}$ ) was performed and followed by a decremental PEEP trial to achieve the minimal elastance of the respiratory system (Ers) (18).

\section{Variability of $\mathrm{V}_{\mathrm{T}}$ Values}

Noisy ventilation was applied on a breath-to-breath basis as sequence of randomly generated $\mathrm{V}_{\mathrm{T}}$ values $(\mathrm{n}=600$; mean, $6 \mathrm{ml} / \mathrm{kg})(7,8)$. The coefficient of variation was $40 \%$, corresponding approximately to the variability in healthy spontaneously breathing subjects (6) and capable of maximizing oxygenation (19). The breath-by-breath $\mathrm{f}$ was maintained constant. The flow rate was $30 \mathrm{~L} / \mathrm{min}$ and active inspiratory time was adjusted at each cycle to achieve the target Vт. Because the inspiratory/ expiratory ratio was fixed at 1:1, the inspiratory pause varied. The minute volume for one cycle of 600 breaths, but not for single breaths, was constant. After completion of the sequence, the system looped itself.

\section{Measurements}

Respiratory mechanics, gas exchange, and hemodynamics were assessed at baseline, at injury, and at 1-hour intervals thereafter (time 1 to 6). PBF was marked with intravenously administered fluorescent microspheres at baseline, at injury, and at time 6 (20). Samples were obtained from the first whole lung bronchoalveolar lavage (BAL) and from a lavage performed immediately before killing animals. Lungs were removed at continuous airway pressures equal to PEEP. The left and right lungs were used for microspheres and tissue analysis, respectively. Diffuse alveolar damage (DAD) was evaluated by an expert blinded to the groups (21). Gene expression of IL- 6 , IL- 8 , transforming growth factor- $\beta$ (TGF- $\beta$ ), amphiregulin, and tenascin-c (TNC) was analyzed using quantitative realtime polymerase chain reaction. Plasma, BAL, and lung tissue cytokine levels were measured by commercially available ELISA kits.

\section{Statistical Analysis}

Data are presented as mean \pm SD unless indicated otherwise. Student's $t$ test, one-way analysis of variance (ANOVA), repeatedmeasurements ANOVA, Mann-Whitney $U$ tests, and Wilcoxon's test were used as appropriate. Effects of noisy ventilation were tested separately in ARDSnet and OLA groups. Associations between two variables were determined with Spearman's rank correlation. Tests were performed using the SPSS software package (SPSS version 15.0, Chicago, IL), multiple comparisons adjusted according to the Bonferroni procedure, and statistical significance was accepted at $P<0.05$.

\section{RESULTS}

\section{General Aspects}

Body weight, number of lavages (Table E1), and functional parameters at baseline (Figure 1, Table 2) did not differ between groups. Adjusted PEEP values in the OLA and OLA+noisy groups were identical in both groups $\left(15.1 \pm 1.5 \mathrm{~cm} \mathrm{H}_{2} \mathrm{O}\right)$. PEEP in the ARDSnet and ARDSnet+noisy groups were fixed at $12 \mathrm{~cm}$ $\mathrm{H}_{2} \mathrm{O}$ according to a previously published table (2).

\section{Respiratory Parameters}

Mean VT, f, and minute ventilation did not differ between groups during the experiment (Table 2). The coefficient of variation of $\mathrm{V}_{\mathrm{T}}$ was higher in the groups with noisy ventilation.

Noisy ventilation led to lower mean and peak airway pressures (Pmean and Ppeak, respectively) and to lower Ers as compared with the ARDSnet and OLA groups (Figure 2) while not affecting the resistance of the respiratory system.

\section{Gas Exchange}

Noisy ventilation improved $\mathrm{PA}_{\mathrm{O}_{2}} / \mathrm{FI}_{\mathrm{O}_{2}}$ compared with the ARDSnet protocol and OLA (Figures 1A and 1B) while decreasing intrapulmonary shunt when compared with ARDSnet protocol (Figure 1C) but not OLA (Figure 1D) and without affecting $\mathrm{Pa}_{\mathrm{CO}_{2}}$ (Figures $1 \mathrm{E}$ and $1 \mathrm{~F}$ ).

\section{Hemodynamics}

Heart rate, mean arterial blood pressure, and cardiac output did not differ between groups (Table E4). Mean pulmonary arterial blood pressure was lower with noisy ventilation compared with ARDSnet. Other variables did not differ between groups.

\section{Distribution of PBF}

Distribution of PBF in one representative animal per group is illustrated in Figure 3. Data on angular coefficients of relative $\mathrm{PBF}$ are presented in Table 3.

In all groups, ALI led to redistribution of PBF from dorsal to ventral, from caudal to cranial, and from central to peripheral lung zones. At time 6 compared with injury, all mechanical ventilation modes led to a redistribution of PBF toward dorsal

TABLE 1. VENTILATOR SETTINGS

\begin{tabular}{|c|c|c|c|c|c|}
\hline & Baseline/Injury & ARDSnet & ARDSnet + noisy & OLA & OLA+noisy \\
\hline $\mathrm{FiO} 2$ & 0.5 & 0.7 & 0.7 & 0.7 & 0.7 \\
\hline RR, per minute & $\begin{array}{l}\text { 12-20 according } \\
\text { to normocapnia }\end{array}$ & $\begin{array}{l}20-40 \text { to achieve } \\
\mathrm{pH}>7.2\end{array}$ & $\begin{array}{l}20-40 \text { to achieve } \\
\mathrm{pH}>7.2\end{array}$ & $\begin{array}{l}20-40 \text { to achieve } \\
\mathrm{pH}>7.2\end{array}$ & $\begin{array}{l}20-40 \text { to achieve } \\
\mathrm{pH}>7.2\end{array}$ \\
\hline $\mathrm{Vt}, \mathrm{ml} / \mathrm{kg}$ & 12 & 6 & variable, mean $=6$ & 6 & variable, mean $=6$ \\
\hline PEEP, $\mathrm{cm} \mathrm{H} \mathrm{H}_{2} \mathrm{O}$ & 5 & 12 & 12 & According to PEEP trial & According to PEEP trial \\
\hline $\mathrm{I}: \mathrm{E}$ & $1: 1$ & $1: 1$ & $1: 1$ & $1: 1$ & $1: 1$ \\
\hline Flow, L/minute & 30 & 30 & 30 & 30 & 30 \\
\hline
\end{tabular}

Definition of abbreviations: ARDSnet = ventilation according to the ARDS Network protocol; Flow = inspiratory gas flow; l:E = ratio of total inspiratory to expiratory time; noisy $=$ application of variable $\mathrm{VT}_{T}($ mean $=6 \mathrm{ml} / \mathrm{kg}$, coefficient of variation $=40 \%$ ); OLA $=$ ventilation according to the open lung approach; PEEP = positive end-expiratory pressure; RR = respiratory rate. 
A
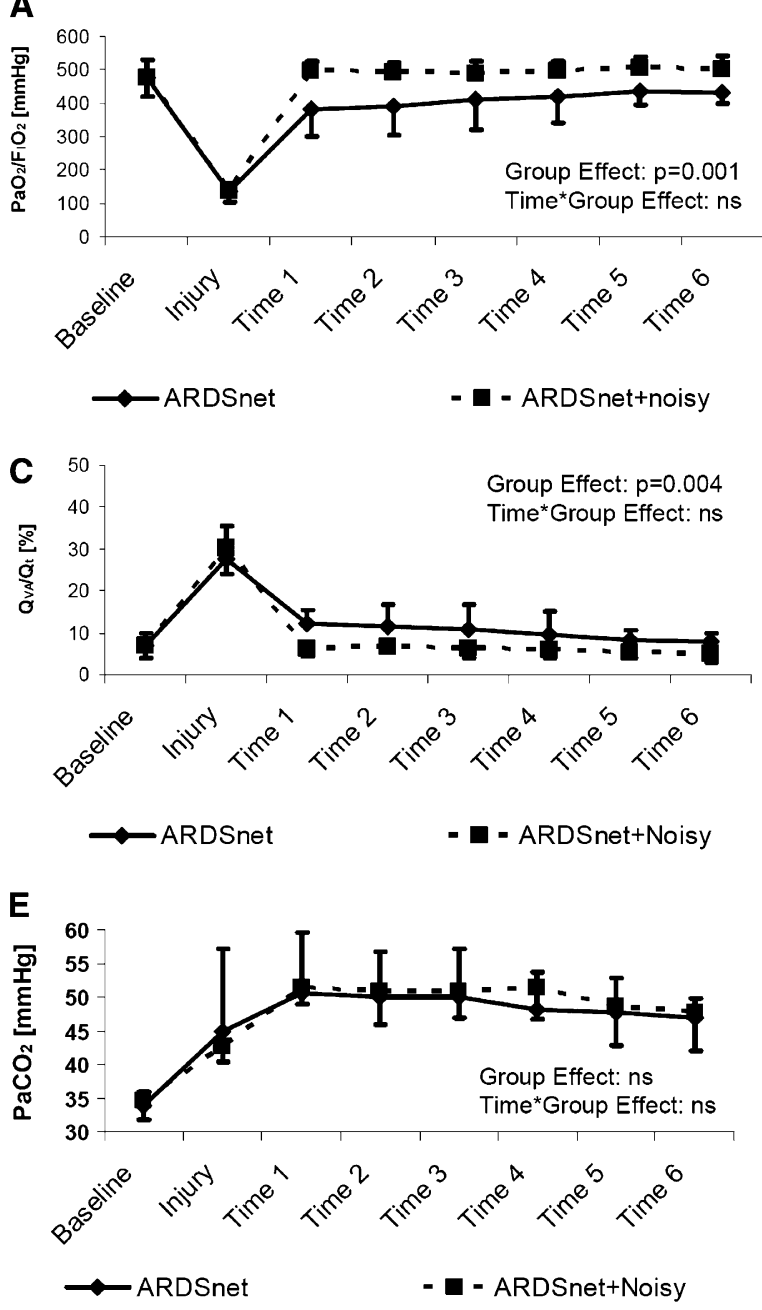
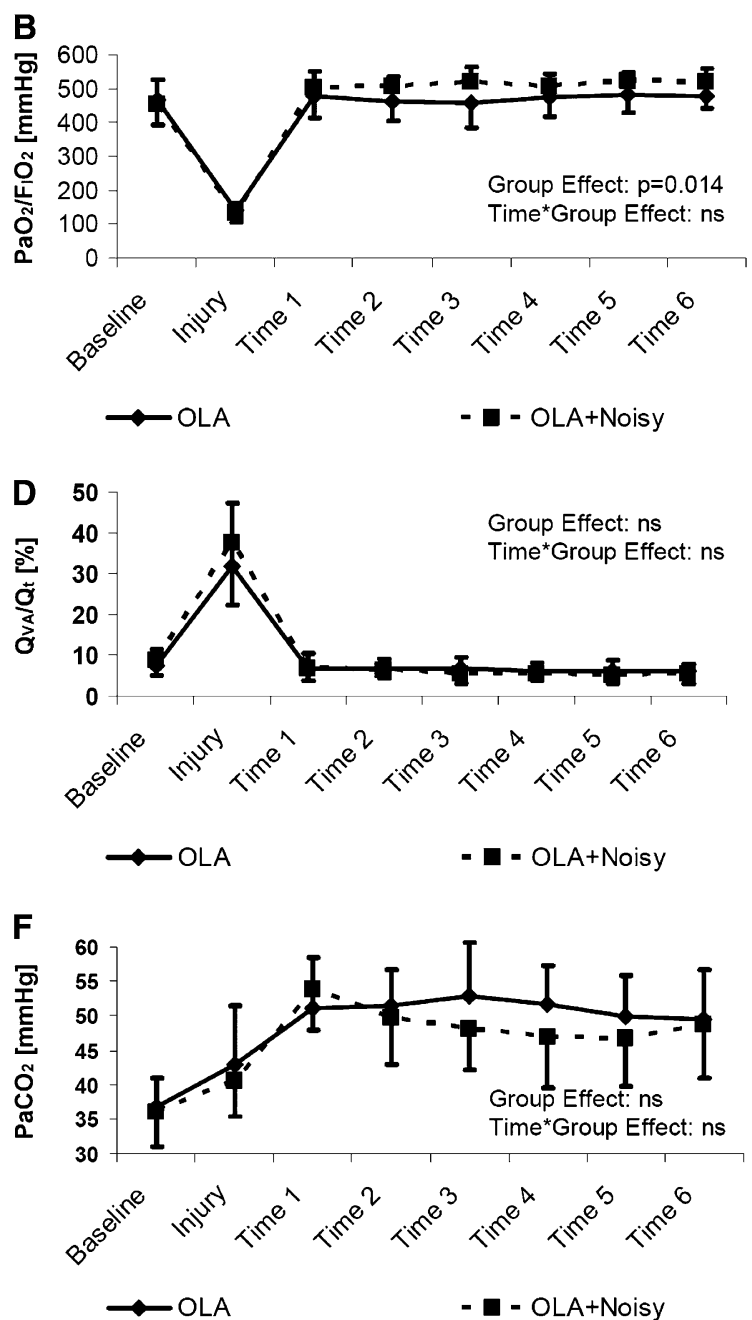

Figure 1. Effects of variable tidal volumes (Noisy) combined with the ARDS Network protocol (ARDSnet) and the open lung approach (OLA) on $\mathrm{PA}_{\mathrm{O}_{2}}$ $(A$ and $B)$ venous admixture $\left(\mathrm{Q}_{\mathrm{VA}} / \mathrm{Qt}\right)(C$ and $D)$ and $\mathrm{PA}_{\mathrm{CO}_{2}}(E$ and $F)$. Values are given as mean and standard deviation. Group and Time $\times$ Group effects were assessed by general linear model statistics. Statistical significance was accepted at $P<0.05$.

regions, whereas a redistribution of PBF toward cranial areas was observed with OLA and noisy ventilation combined with both protective strategies. ARDSnet and OLA redistributed PBF toward central areas, whereas noisy ventilation did not. Comparisons at time 6 showed that noisy ventilation did not affect dorsal-ventral distributions of PBF. However, noisy ventilation redistributed PBF toward caudal areas compared with ARDSnet and toward peripheral zones compared with OLA.

Noisy ventilation reduced the overall DAD score compared with both protective ventilation strategies (Figure 4). Compared with ARDSnet, noisy ventilation reduced the DAD score in dependent regions. In the ARDSnet group, noisy ventilation reduced interstitial edema, hemorrhage, and epithelial destruction mainly in dependent zones (Table 4). In contrast, noisy ventilation reduced overdistension mainly in nondependent regions in OLA.

\section{Pulmonary Mechanical Stress Markers and Inflammatory Response}

In ARDSnet and OLA, noisy ventilation did not increase gene expression of amphiregulin, TNC, IL-6, IL-8, or TGF- $\beta$ in dependent and nondependent lung regions (Table 5). Independent from the mode of ventilation, gene-expression of IL-8, and mechanical stress markers were increased in nondependent compared with dependent lung regions (IL-8, 0.88 [0.69-1.74] vs. 0.20 [0.07-0.86], $P=0.002$; amphiregulin, 0.62 [0.36-1.43] vs. $0.56[0.15-0.97], P=0.008$; TNC, 0.79 [0.58-1.72] vs. 0.32 [0.100.56 ], $P<0.001$ ). The cytokine levels of IL-6 in plasma (see Fig. E8 in the online supplement), as well as of IL-6 and IL-8 in lung tissue (Tables E5 and E6, respectively) and in BAL (Table E7), were not influenced by noisy ventilation in ARDSnet and OLA groups, but tissue levels of IL-6 and IL-8 were higher in dependent than nondependent lung zones $(P<0.001)$.

\section{Association Analysis}

$\mathrm{PA}_{\mathrm{O}_{2}} / \mathrm{FI}_{\mathrm{O}_{2}}$ was negatively correlated with the angular coefficients of the distribution of PBF along the caudal-cranial axis $\left(r^{2}=\right.$ $0.47, P<0.001)$ and positively correlated with the angular coefficients of the distribution of PBF along the peripheralcentral axis $\left(r^{2}=0.11, P=0.045\right)$. Ers was negatively correlated with $\mathrm{PA}_{\mathrm{O}_{2}} / \mathrm{FI}_{\mathrm{O}_{2}}\left(r^{2}=0.26, P=0.002\right)$ and positively correlated with the mean gene-expression of amphiregulin as well as of mean protein levels of IL-6 and IL-8 in lung tissue $\left(r^{2}=0.13\right.$, $\left.P=0.047 ; r^{2}=0.19, P=0.012 ; r^{2}=0.26, P=0.003\right)$. Pmean and Ppeak were correlated with the mean gene expression of TNC $\left(r^{2}=0.14, P=0.035\right.$ and $r^{2}=0.12, P=0.048$, respectively). 


\begin{tabular}{|c|c|c|c|c|c|c|c|c|c|c|c|c|}
\hline Parameter* & Group & Baseline & Injury & Time 1 & Time 2 & Time 3 & Time 4 & Time 5 & Time 6 & $\begin{array}{l}\text { Baseline } \\
\text { vs. Injury }\end{array}$ & $\begin{array}{l}\text { Group } \\
\text { Effect }\end{array}$ & $\begin{array}{c}\text { Time } \\
\times \\
\text { Group } \\
\text { Effect }\end{array}$ \\
\hline \multirow[t]{5}{*}{$\mathrm{V}_{\mathrm{T}}, \mathrm{ml} / \mathrm{kg}$} & & & & & & & & & & ns & & \\
\hline & ARDSnet & $9.3 \pm 0.8$ & $9.2 \pm 0.7$ & $6.1 \pm 0.6$ & $6.2 \pm 0.7$ & $6.2 \pm 0.6$ & $6.2 \pm 0.5$ & $6.0 \pm 0.3$ & $6.0 \pm 0.3$ & & ns & ns \\
\hline & ARDSnet + noisy & $9.5 \pm 0.4$ & $9.4 \pm 0.7$ & $5.7 \pm 1.0$ & $5.7 \pm 0.7$ & $5.8 \pm 1.1$ & $6.0 \pm 1.1$ & $5.7 \pm 0.5$ & $6.1 \pm 1.5$ & & & \\
\hline & OLA & $9.5 \pm 0.6$ & $9.7 \pm 0.7$ & $6.0 \pm 0.5$ & $6.1 \pm 0.5$ & $6.0 \pm 0.4$ & $5.9 \pm 0.2$ & $6.1 \pm 0.7$ & $6.0 \pm 0.4$ & & ns & ns \\
\hline & OLA+noisy & $9.8 \pm 0.5$ & $9.6 \pm 0.6$ & $6.1 \pm 0.8$ & $6.2 \pm 0.8$ & $6.0 \pm 0.7$ & $6.0 \pm 0.6$ & $6.1 \pm 1.2$ & $6.2 \pm 1.0$ & & & \\
\hline \multirow{5}{*}{$\mathrm{CV}$ of $\mathrm{V}_{\mathrm{T}}, \%$} & & & & & & & & & & ns & & \\
\hline & ARDSnet & $0.3 \pm 0.1$ & $0.4 \pm 0.2$ & $1.7 \pm 3.6$ & $1.0 \pm 1.1$ & $1.5 \pm 0.8$ & $1.2 \pm 1.1$ & $1.5 \pm 2.8$ & $0.8 \pm 0.3$ & & $P<0.001$ & ns \\
\hline & ARDSnet + noisy & $0.3 \pm 0.1$ & $0.4 \pm 0.3$ & $40.1 \pm 2.6$ & $40.0 \pm 2.7$ & $40.1 \pm 2.6$ & $39.8 \pm 3.4$ & $39.9 \pm 3.6$ & $41.2 \pm 2.5$ & & & \\
\hline & OLA & $0.4 \pm 0.3$ & $0.4 \pm 0.2$ & $0.7 \pm 0.3$ & $0.8 \pm 0.6$ & $0.7 \pm 0.3$ & $1.0 \pm 0.6$ & $0.9 \pm 0.7$ & $0.8 \pm 0.6$ & & $P<0.001$ & ns \\
\hline & OLA+noisy & $0.3 \pm 0.1$ & $0.6 \pm 0.7$ & $38.8 \pm 2.9$ & $40.5 \pm 2.4$ & $38.7 \pm 3.4$ & $38.2 \pm 2.7$ & $40.2 \pm 3.4$ & $39.8 \pm 1.7$ & & & \\
\hline \multirow[t]{5}{*}{ f, per minute } & & & & & & & & & & ns & & \\
\hline & ARDSnet & $17.9 \pm 4.6$ & $17.4 \pm 4.9$ & $26.7 \pm 5.2$ & $27.2 \pm 6.0$ & $27.2 \pm 6.0$ & $27.6 \pm 5.9$ & $27.6 \pm 5.9$ & $27.6 \pm 5.9$ & & ns & ns \\
\hline & ARDSnet+noisy & $16.8 \pm 5.0$ & $17.2 \pm 4.7$ & $28.3 \pm 4.4$ & $28.6 \pm 4.4$ & $28.6 \pm 4.4$ & $28.6 \pm 4.4$ & $28.6 \pm 4.4$ & $28.6 \pm 4.4$ & & & \\
\hline & OLA & $17.1 \pm 5.1$ & $16.4 \pm 3.2$ & $28.6 \pm 9.1$ & $28.6 \pm 9.1$ & $28.6 \pm 9.1$ & $28.6 \pm 9.1$ & $28.6 \pm 9.1$ & $28.6 \pm 9.1$ & & ns & ns \\
\hline & OLA+noisy & $17.6 \pm 5.0$ & $18.0 \pm 4.1$ & $27.3 \pm 3.4$ & $29.1 \pm 4.9$ & $29.4 \pm 5.1$ & $29.4 \pm 5.1$ & $29.4 \pm 5.1$ & $29.4 \pm 5.1$ & & & \\
\hline \multirow[t]{5}{*}{$\dot{\mathrm{V}}_{\mathrm{E}}, \mathrm{L} /$ minute } & & & & & & & & & & ns & & \\
\hline & ARDSnet & $5.2 \pm 1.1$ & $5.0 \pm 1.0$ & $5.1 \pm 1.0$ & $5.3 \pm 1.0$ & $5.3 \pm 1.1$ & $5.4 \pm 0.8$ & $5.2 \pm 0.8$ & $5.2 \pm 0.9$ & & ns & ns \\
\hline & ARDSnet + noisy & $4.6 \pm 1.3$ & $4.6 \pm 1.2$ & $4.6 \pm 1.0$ & $4.6 \pm 0.7$ & $4.8 \pm 1.2$ & $4.9 \pm 1.1$ & $4.7 \pm 0.8$ & $5.0 \pm 1.5$ & & & \\
\hline & OLA & $4.7 \pm 1.1$ & $4.6 \pm 0.8$ & $5.0 \pm 1.6$ & $5.1 \pm 1.6$ & $5.0 \pm 1.5$ & $4.9 \pm 1.3$ & $5.1 \pm 1.8$ & $5.0 \pm 1.4$ & & ns & ns \\
\hline & OLA+noisy & $4.8 \pm 1.1$ & $4.8 \pm 0.6$ & $4.7 \pm 0.6$ & $5.0 \pm 0.6$ & $5.0 \pm 0.7$ & $5.0 \pm 0.7$ & $5.1 \pm 1.1$ & $5.2 \pm 0.9$ & & & \\
\hline \multirow{5}{*}{ Rrs, $\mathrm{cm} \mathrm{H} \mathrm{H}_{2} \mathrm{O} / \mathrm{L} / \mathrm{s}$} & & & & & & & & & & $P=0.002$ & & \\
\hline & ARDSnet & $4.9 \pm 0.9$ & $5.8 \pm 1.7$ & $3.5 \pm 1.6$ & $3.9 \pm 0.7$ & $3.8 \pm 0.9$ & $3.6 \pm 1.0$ & $3.9 \pm 1.1$ & $3.9 \pm 1.6$ & & ns & ns \\
\hline & ARDSnet + noisy & $4.8 \pm 0.8$ & $7.9 \pm 5.8$ & $4.1 \pm 1.3$ & $4.1 \pm 1.4$ & $3.8 \pm 1.2$ & $3.6 \pm 0.8$ & $3.8 \pm 0.8$ & $3.8 \pm 1.0$ & & & \\
\hline & OLA & $5.2 \pm 1.0$ & $8.4 \pm 5.4$ & $4.1 \pm 1.7$ & $3.8 \pm 1.6$ & $3.8 \pm 1.5$ & $3.6 \pm 1.5$ & $3.7 \pm 1.5$ & $3.7 \pm 1.4$ & & ns & ns \\
\hline & OLA+noisy & $5.7 \pm 2.1$ & $7.7 \pm 2.8$ & $4.3 \pm 1.1$ & $3.9 \pm 0.8$ & $3.9 \pm 0.7$ & $3.9 \pm 0.8$ & $3.7 \pm 1.0$ & $3.8 \pm 0.9$ & & & \\
\hline \multirow[t]{5}{*}{ PEEPi, $\mathrm{cm} \mathrm{H} \mathrm{H}_{2} \mathrm{O}$} & & & & & & & & & & ns & & \\
\hline & ARDSnet & $0.1 \pm 0.1$ & $0.1 \pm 0.1$ & $0.2 \pm 0.2$ & $0.2 \pm 0.1$ & $0.2 \pm 0.2$ & $0.2 \pm 0.2$ & $0.1 \pm 0.2$ & $0.1 \pm 0.1$ & & $P=0.005$ & ns \\
\hline & ARDSnet + noisy & $0.1 \pm 0.1$ & $0.1 \pm 0.1$ & $0.2 \pm 0.1$ & $0.2 \pm 0.1$ & $0.2 \pm 0.2$ & $0.2 \pm 0.1$ & $0.2 \pm 0.1$ & $0.2 \pm 0.1$ & & & \\
\hline & OLA & $0.1 \pm 0.1$ & $0.2 \pm 0.5$ & $0.1 \pm 0.1$ & $0.2 \pm 0.1$ & $0.1 \pm 0.1$ & $0.1 \pm 0.1$ & $0.1 \pm 0.1$ & $0.1 \pm 0.1$ & & ns & ns \\
\hline & OLA+noisy & $0.1 \pm 0.1$ & $0.2 \pm 0.2$ & $0.3 \pm 0.1$ & $0.2 \pm 0.1$ & $0.2 \pm 0.1$ & $0.1 \pm 0.1$ & $0.1 \pm 0.1$ & $0.1 \pm 0.1$ & & & \\
\hline
\end{tabular}

Definition of abbreviation: ARDSnet = ventilation according to the ARDS Network protocol; $\mathrm{CV}=$ coefficient of variation; Ers = elastance of the respiratory system; $\dot{\mathrm{V}}_{\mathrm{E}}=$ minute ventilation; noisy = application of variable $\mathrm{VT}_{\mathrm{T}}$ (mean $=6 \mathrm{ml} / \mathrm{kg}$, coefficient of variation $=40 \%$ ); ns = not significant; OLA = ventilation according to the open lung approach; PEEPi = intrinsic positive end-expiratory pressure; Pmean = mean airway pressure; Ppeak = peak airway pressure; $f=$ respiratory frequency; Rrs = resistance of the respiratory system.

* Values are given as mean and SD. Effects of Injury on variables were tested with paired $t$ tests (Baseline vs. Injury). Differences between and within groups (Group Effect; Time $\times$ Group Effect, respectively) were tested with general linear model statistics and adjusted for repeated measurements. Statistical significance was accepted at $P<0.05$.

\section{DISCUSSION}

In a surfactant depletion model of ALI, we found that noisy ventilation with variable VT and fixed RF (1) improved arterial oxygenation and reduced mean Ppeak and Ers compared with ARDSnet and OLA, (2) redistributed PBF to caudal zones compared with ARDSnet and to peripheral ones compared with OLA, (3) reduced histological damage in comparison to both protective ventilation strategies, and (4) did not increase lung inflammation or mechanical stress.

\section{Noisy Ventilation and Respiratory Function}

Our data confirm previous observations suggesting beneficial effects of noisy ventilation to improve respiratory function. In a first report on natural noisy ventilation, Lefevre and colleagues (22) showed an improvement in oxygenation, respiratory system compliance, and lung water content through variation of $\mathrm{V}_{\mathrm{T}}$ and $\mathrm{f}$, as compared with conventional ventilation. However, significant differences in $\mathrm{PACO}_{2}, p H$, and delivered $\mathrm{V}_{\mathrm{T}}$ between ventilation groups, as well as the absence of PEEP, could have influenced their results. In a porcine oleic acid model of ALI, Boker and colleagues showed that natural noisy ventilation improved oxygenation but not respiratory system compliance when using low tidal volumes (13). In a similar model of ALI, Funk and colleagues reported improvements of oxygenation and respiratory system compliance when comparing natural noisy ventilation and OLA (23). In contrast, in a canine oleic acid model of ALI, Nam and colleagues could not show any beneficial effect of natural noisy ventilation (14). However, differently from other studies, those authors used higher $\mathrm{V}_{\mathrm{T}}$ (approximately $15 \mathrm{ml} / \mathrm{kg}$ ) and no PEEP. Moreover, the mortality of animals was high, indicating more severe lung injury. Our study differs from previous ones in the following respects: (1) Only VT was modulated, whereas other authors $(8,11,13)$ varied simultaneously $f$ and $V_{T}$, maintaining a constant minute ventilation on a cycle-by-cycle basis. Therefore, our results suggest that $\mathrm{VT}_{\mathrm{T}}$ variability is the main determinant for improvement in respiratory function. (2) We used a stable surfactant depletion model of ALI, and all animals survived the observation period without need for vasoactive drugs, which are usually required during oleic acid injury (24). (3) f and $\mathrm{V}_{\mathrm{T}}$ were strictly controlled, and the combination of PEEP and $\mathrm{FI}_{\mathrm{O}_{2}}$, were selected according to the ARDSnet recommendations. (4) In OLA, PEEP was selected to minimize Ers, contributing to keep the lung open over time. Thus, in our study, protective ventilatory strategies with and without lung recruitment were optimized according to current standards in mechanical ventilation. 

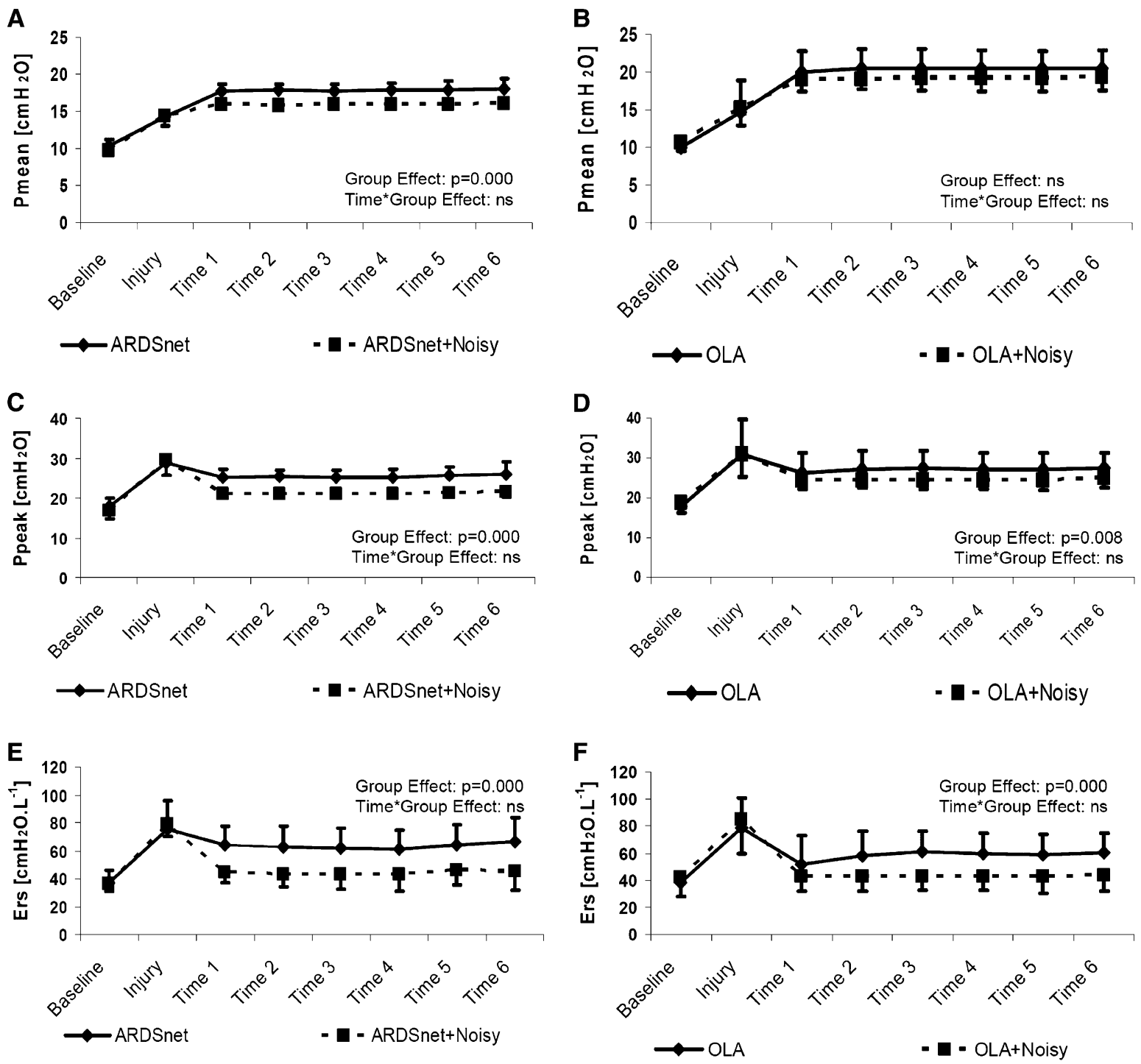

Figure 2. Effects of variable tidal volumes (Noisy) combined with the ARDS Network protocol (ARDSnet) and the open lung approach (OLA) on mean airway pressure (Pmean) ( $A$ and $B$ ) mean peak airway pressure (Ppeak) ( $\left.\mathrm{Q}_{\mathrm{VA}} / \mathrm{Qt}\right)(C$ and $D)$ and elastance of the respiratory system (Ers) $(E$ and $F$ ). Values are given as mean and standard deviation. Group and Time $\times$ Group effects were assessed by general linear model statistics. Statistical significance was accepted at $P<0.05$.

Independent from the protective ventilation strategy we used, noisy ventilation improved arterial oxygenation and Ers at a lower mean Ppeak. Several mechanisms can explain such findings: (1) The occasional proportionally higher VT occurring during noisy ventilation may recruit atelectactic zones $(9,11)$, (2) redistribution of PBF toward better aerated lung areas may improve ventilation/perfusion matching (25), (3) increased release of surfactant (26), (4) stochastic resonance behavior of the respiratory system (noise enhancement of an input signal, e.g., Vт [7]), and (5) enhanced respiratory sinus arrhythmia (27).

The improvement in Ers and Ppeak with ARDSnet and OLA suggest that recruitment of atelectactic zones played an important role. In ALI induced by oleic acid or surfactant depletion, improved arterial oxygenation and compliance reflect recruitment of atelectactic zones as assessed by computer tomography $(28,29)$.

Redistribution of PBF toward caudal and peripheral lung regions likely reflected better aeration/ventilation resulting from recruitment in those areas as shown by the correlation analysis. In oleic acid and surfactant depletion-induced ALI, Karmrodt and colleagues (30) have shown that aeration in caudal lung zones increased as a function of recruitment. Moreover, mainly in ARDSnet, noisy ventilation reduced Pmean and mean pulmonary arterial pressure, likely favoring redistribution of PBF.

\section{Noisy Ventilation and Lung Injury}

It has been shown that mechanical ventilation with high $V_{T}$ leads to ventilator associated lung injury (VALI) (31). When the global applied force on the lung parenchyma is excessive or the fibers near the diseased regions experience excessive mechanical stress, mechanical rupture and/or biological activation of inflammation may occur $(32,33)$, activating or worsening lung injury. In line with these claims, in our study, we found that increased gene expression was associated with higher Ppeak and Pmean, whereas decreased Ers was correlated with increased gene-expression of inflammatory mediators. Although much has been learned regarding the ability of pulmonary cells to sense and integrate information from mechanical distortion during monotonic controlled ventilation (34), little is known about the effects of variable mechanical ventilation. 


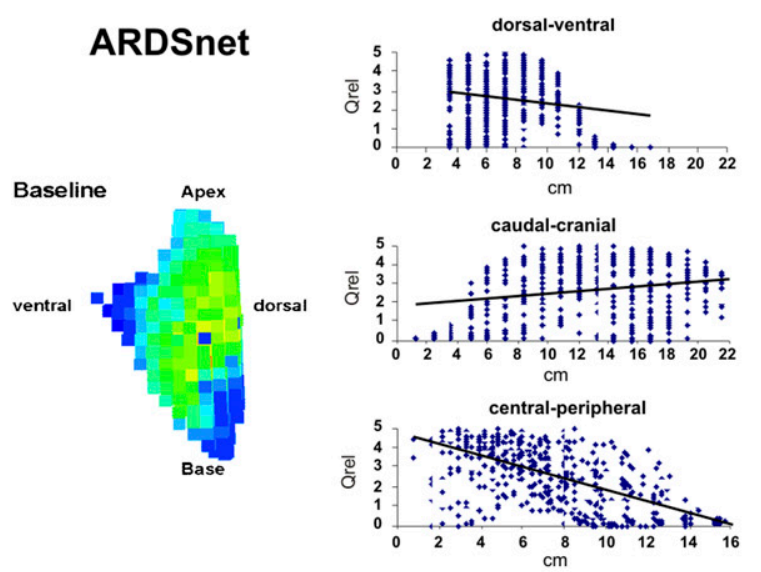

\section{ARDSnet+noisy}

Baseline
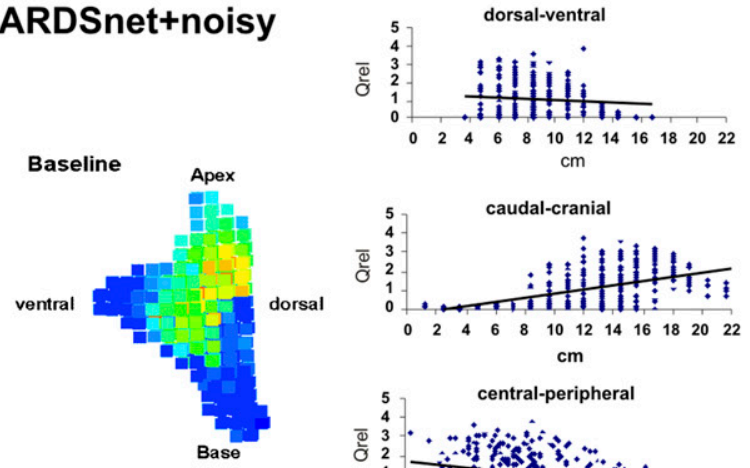

$\mathrm{cm}$

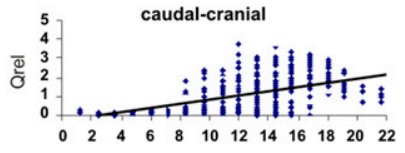

cm
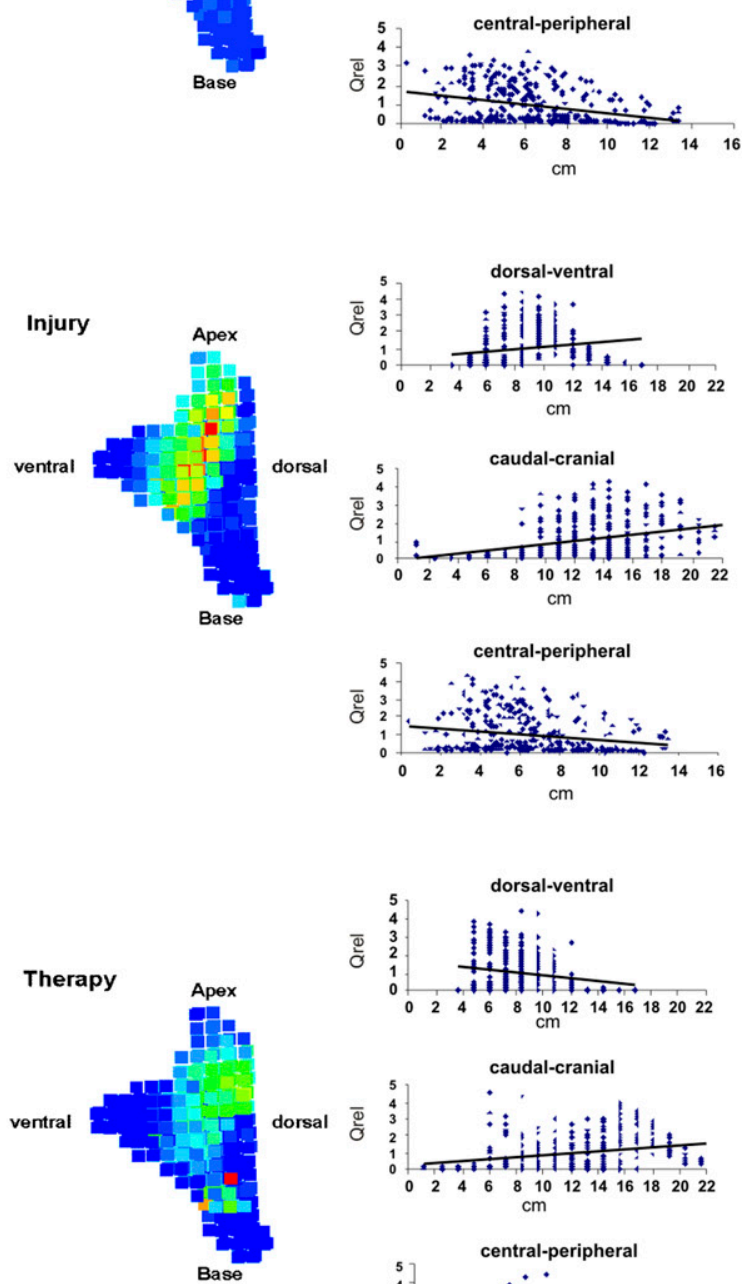

$\mathrm{cm}$
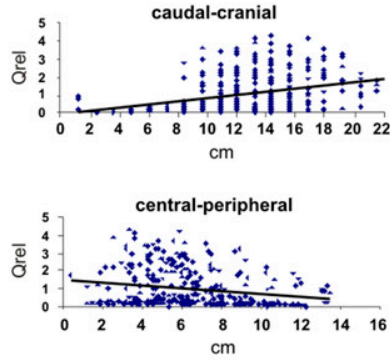

dorsal-ventral

बढ़
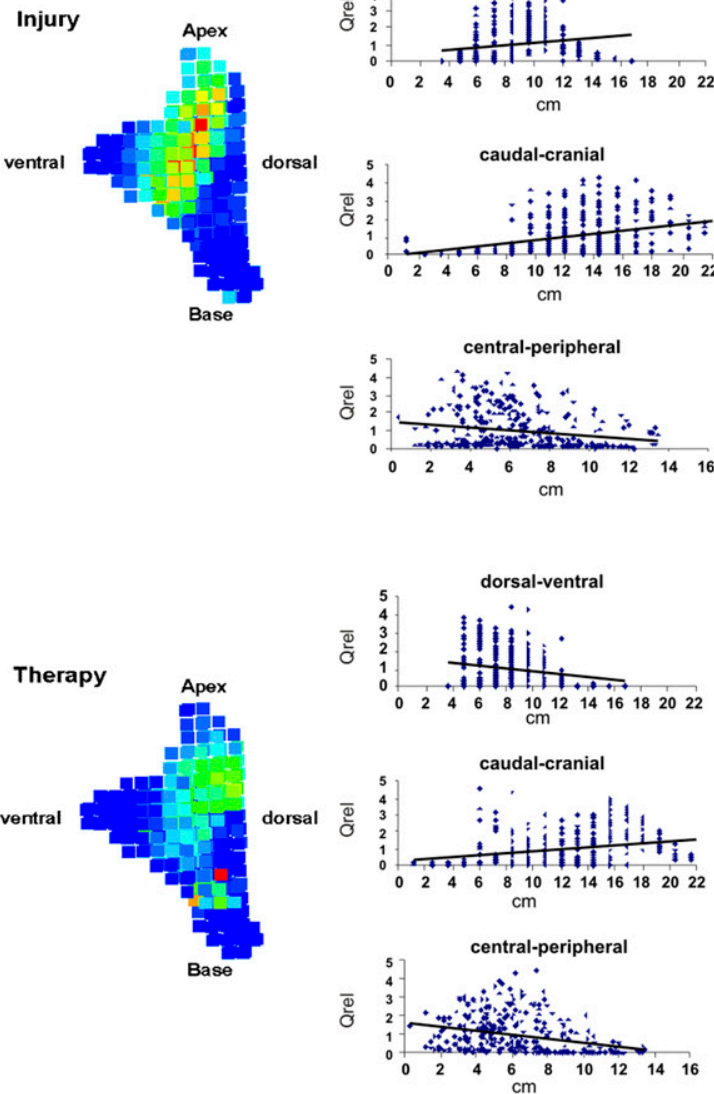

Figure 3. Regional distribution of pulmonary blood flow in four representative animals at baseline (upper row), after injury (middle row), and after 6 hours of protective mechanical ventilation according $(A)$ the ARDS Network protocol (ARDSnet) and (B) the open lung approach (OLA) with and without variable tidal volumes (noisy) (lower row: Therapy). Blue represents lowest and red highest relative pulmonary blood flow (Q̈rel), respectively, in each condition. Straight lines in the scatter plots represent linear regression of (Q̈rel) along the central-peripheral (X), dorsal-ventral ( $Y$ ), and caudal-cranial (Z) axes.

To our knowledge, this is the first study showing that noisy ventilation is able to attenuate lung histological damage and to demonstrate that it does not increase gene expression or release of proinflammatory markers of lung injury. Although Funk and colleagues (23) reported that natural noisy or fractal ventilation did not worsen lung histological lung appearance compared with conventional monotonic ventilation, in the present study animals developed less interstitial edema, hemorrhage, and epithelial destruction, especially in the dependent lung regions, compared with ARDSnet. On the other hand, compared with OLA, noisy ventilation resulted in reduction of $\mathrm{DAD}$, mainly due to decreased overdistension in nondependent regions.

Our data suggest that noisy ventilation can reduce VALI by different mechanisms, depending on the protective mechanical ventilation strategy it is used in combination with. In ARDSnet it seems likely that dependent lung zones were not fully recruited, leading to cyclic opening/closing of atelectactic areas and peripheral airways. This could explain our findings of prevalent histological damage in the dependent lung areas in 

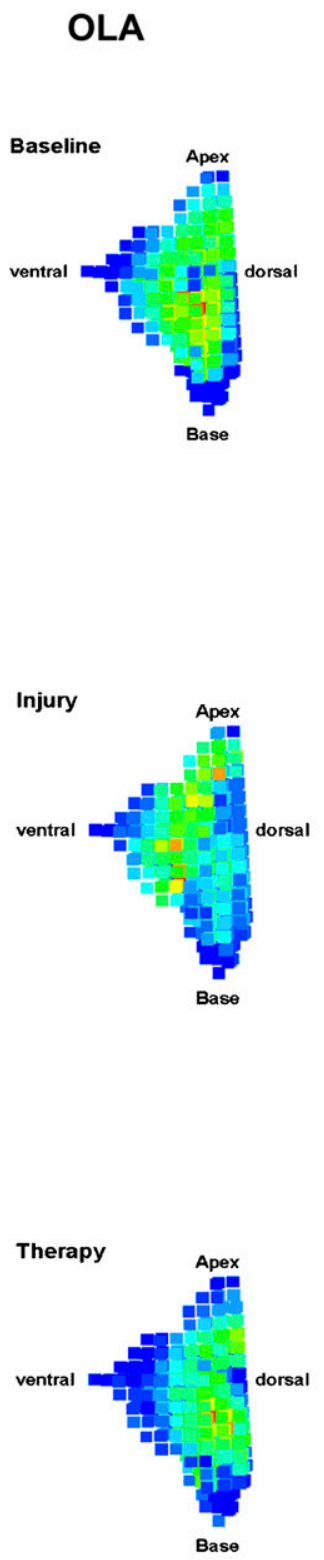
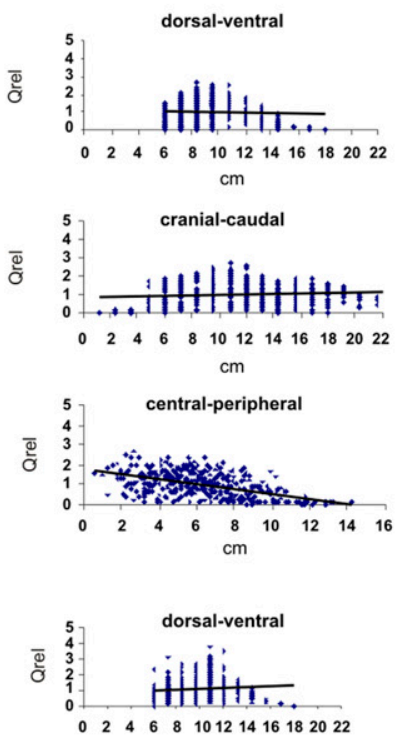

$\mathrm{cm}$

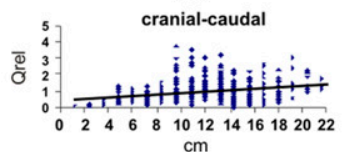

$\mathrm{cm}$
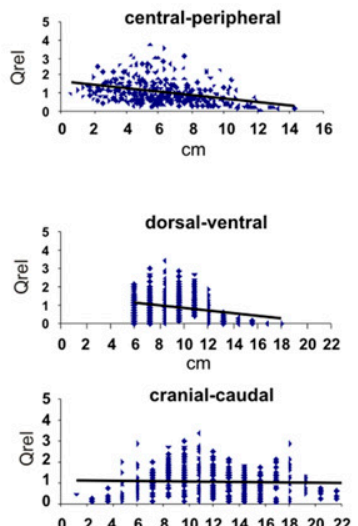

$\begin{array}{lllllllll}0 & 2 & 4 & 6 & 8 & 10121416182022\end{array}$

$\mathrm{cm}$

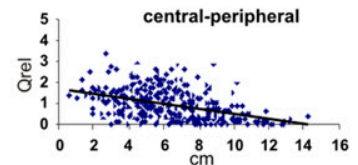

OLA+noisy
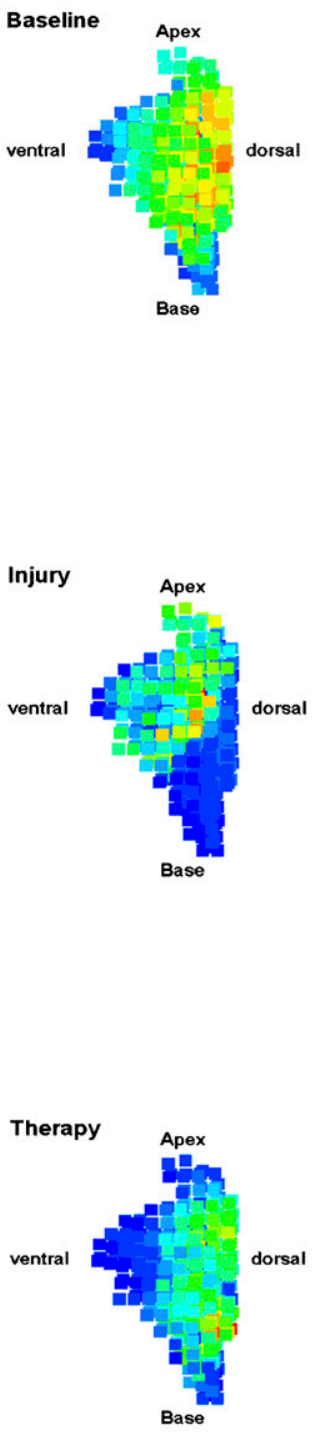

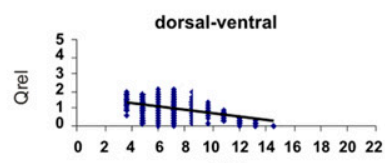

cm

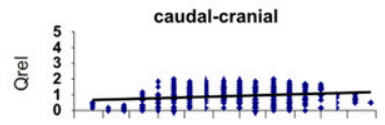

$\begin{array}{lllllllllllll}0 & 2 & 4 & 6 & 8 & 10 & 12 & 14 & 16 & 18 & 20 & 22\end{array}$

$\mathrm{cm}$
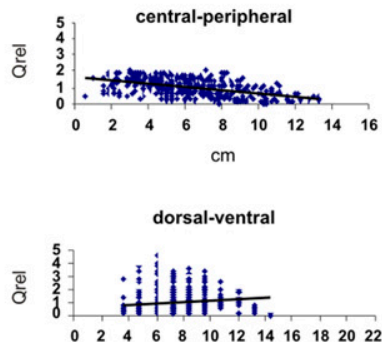

$\mathrm{cm}$

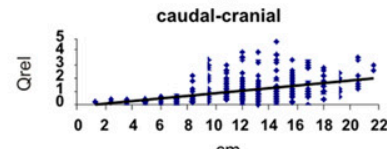

central-peripheral

ळ్ర
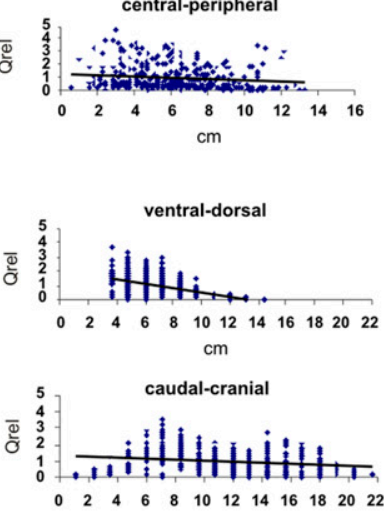

$\mathrm{cm}$

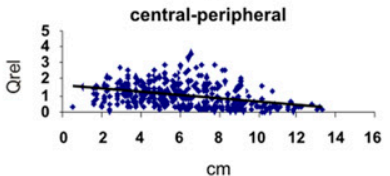

Figure 3. (continued).

this group. In this situation, noisy ventilation may recruit and stabilize the lungs at lower PEEP, thereby reducing injury. On the other hand, when OLA was used, the lungs were possibly fully recruited, with overdistension of nondependent lung regions. Under these conditions, the reduced mean Ppeak during noisy ventilation probably acted to limit overdistension in OLA, with less effect on other features of lung injury. Furthermore, there was no evidence that noisy ventilation increased gene expression of inflammation mediators or their release into BAL, plasma, or lung tissue, which is in agreement with other studies $(13,23)$.

Although not directly related to the use of noisy ventilation, it is worth noting that protein levels of IL-6 and IL-8 were higher in dependent than nondependent zones, while gene expression of inflammation markers showed the opposite pat- tern. There are two possible explanations. First, different time dynamics may have played a role. Dependent areas may have developed inflammation immediately after lavage, but because they developed atelectasis and/or edema, they were less ventilated. Accordingly, gene expression was more closely related to the effects of VALI in nondependent zones, which occurred later on the course of injury. Second, cytokines may have cumulated preferentially in dependent zones due to the gravity gradient.

It could be argued that mechanical stress could still be higher with noisy ventilation despite similar inflammatory activation. However, the analysis of gene expression of amphiregulin and TNC, which in contrast to IL-6, IL- 8 , and TGF- $\beta$ are activated selectively by mechanotransduction (35), largely rules out this hypothesis. 
TABLE 3. ANGULAR COEFFICIENTS OF RELATIVE PULMONARY BLOOD FLOW*

\begin{tabular}{|c|c|c|c|c|c|c|c|}
\hline Ventilation Mode & Gradient & Baseline & Injury & Time 6 (6 h of Therapy) & $\begin{array}{l}\text { Baseline vs. } \\
\text { Injury }\end{array}$ & $\begin{array}{l}\text { Injury vs. } \\
\text { Time } 6\end{array}$ & Group Effect \\
\hline ARDSnet & Dorsal-ventral & $-0.05(-0.09$ to 0.00$]$ & $0.08(0.03$ to 0.14$)$ & $-0.02(-0.09$ to -0.01$)$ & $P<0.001$ & $P=0.011$ & ns \\
\hline ARDSnet+noisy & Dorsal-ventral & $-0.06(-0.12$ to -0.03$)$ & $0.06(-0.12$ to -0.03$)$ & $-0.08(-0.12$ to -0.02$)$ & & $P=0.013$ & \\
\hline OLA & Dorsal-ventral & $-0.03(-0.05$ to 0.03$)$ & 0.07 (0.04 to 0.09$)$ & $-0.08(-0.12$ to -0.06$)$ & & $P=0.008$ & ns \\
\hline OLA+noisy & Dorsal-ventral & $-0.06(-0.01$ to -0.04$)$ & $0.02(-0.01$ to 0.05$)$ & $-0.14(-0.16$ to -0.12$)$ & & $P=0.008$ & \\
\hline ARDSnet & Caudal-cranial & $0.01(0.01$ to 0.05$)$ & $0.09(0.06$ to 0.1$)$ & 0.04 (0.04 to 0.11$)$ & $P<0.001$ & ns & $P=0.023$ \\
\hline ARDSnet+noisy & Caudal-cranial & $0(-0.02$ to 0.00$)$ & 0.07 (0.06 to 0.09$)$ & $0.01(-0.05$ to 0.04$)$ & & $P=0.008$ & \\
\hline OLA & Caudal-cranial & 0.01 (0.01 to 0.02$)$ & 0.05 (0.05 to 0.07$)$ & $0(-0.01$ to 0.02$)$ & & $P=0.008$ & ns \\
\hline OLA+noisy & Caudal-cranial & $0.02(0-0.05)$ & $0.06(0.04$ to 0.1$)$ & $-0.04(-0.05$ to -0.02$)$ & & $P=0.011$ & \\
\hline ARDSnet & Central-peripheral & $-0.11(-0.15$ to -0.05$)$ & $-0.05(-0.11$ to -0.03$)$ & $-0.14(-0.2$ to -0.1$)$ & $P=0.008$ & $P=0.011$ & ns \\
\hline ARDSnet+noisy & Central-peripheral & $-0.12(-0.14$ to -0.05$)$ & $-0.13(-0.13$ to -0.08$)$ & $-0.11(-0.12$ to -0.08$)$ & & ns & \\
\hline OLA & Central-peripheral & $-0.11(-0.15$ to -0.08$)$ & $-0.04(-0.05$ to -0.03$)$ & $-0.14(-0.17$ to -0.13$)$ & & $P=0.011$ & $P=0.030$ \\
\hline OLA+noisy & Central-peripheral & $-0.13(-0.14$ to -0.11$)$ & $-0.08(-0.14$ to -0.06$)$ & $-0.09(-0.11$ to -0.07$)$ & & ns & \\
\hline
\end{tabular}

Definition of abbreviations: ARDSnet = ventilation according to the ARDS Network protocol; noisy $=$ application of variable $\mathrm{V} \mathrm{T}(\mathrm{mean}=6 \mathrm{ml} / \mathrm{kg}$, coefficient of variation $=$ $40 \%) ; \mathrm{ns}=$ not significant; OLA = ventilation according to the open lung approach.

* Data are shown as medians and interquartile range. Differences between baseline and injury (baseline vs. Injury, before randomization) and between injury and

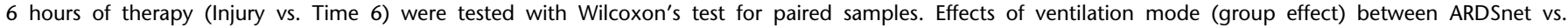
ARDSnet+noisy and OLA vs. OLA+noisy, respectively, were tested with the Mann-Whitney $U$ test. Statistical significance was accepted at $P<0.05$.

Different mechanisms could explain the finding that noisy ventilation reduced VALI and did not influence mechanical stress: (1) Alveolar recruitment resulted in more homogenous distribution of ventilation and improved mechanical properties; (2) transpulmonary pressure was decreased as a result of lower Ers and Ppeak at comparable mean VT; (3) the nonnormal distribution of the respiratory pattern during noisy ventilation led to an increased number of respiratory cycles with $\mathrm{VT}_{\mathrm{T}}<6 \mathrm{ml} / \mathrm{kg}$
(Fig. E5). However, Vt values that are too low can also be injurious (36); (4) monotonic and variable lung straining may have different impacts on VALI.

\section{Limitations}

Our study has several limitations. First, the surfactant depletion model does not reproduce all features of the more complex human ALI/ARDS and is highly recruitable. Second, we did not
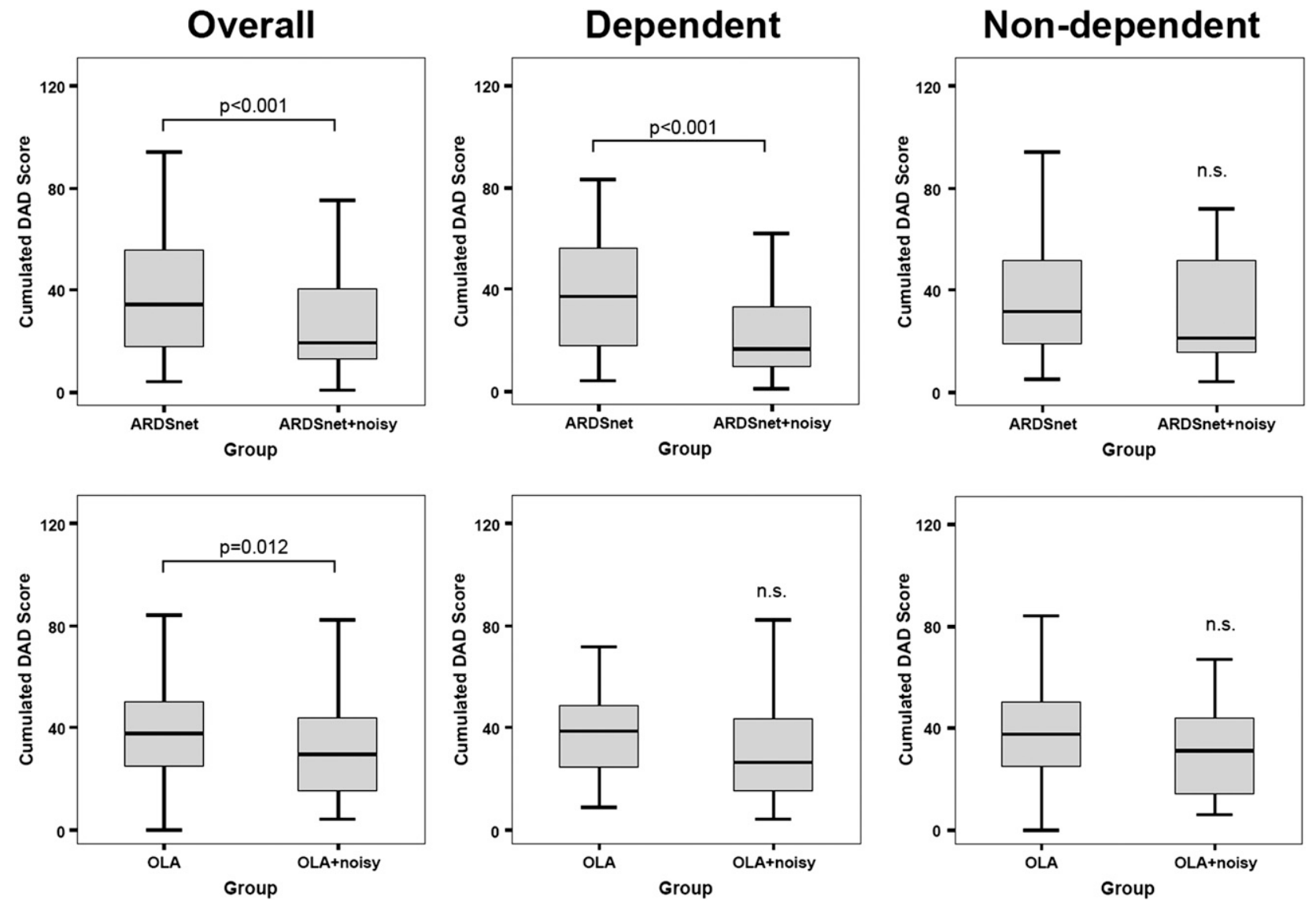

Figure 4. Cumulated diffuse alveolar damage score (DAD) overall (left column) and in dependent (middle column) and nondependent (right column) lung regions after protective mechanical ventilation according the ARDS Network protocol (ARDSnet) and the open lung approach (OLA) with and without variable tidal volumes (noisy). Values are shown as medians, interquartiles, minima, and maxima. Mann-Whitney $U$ Test was used to compare groups. Statistical significance was accepted at $P<0.05$. 
TABLE 4. DIFFUSE ALVEOLAR DAMAGE (DAD) SCORE VARIABLES*

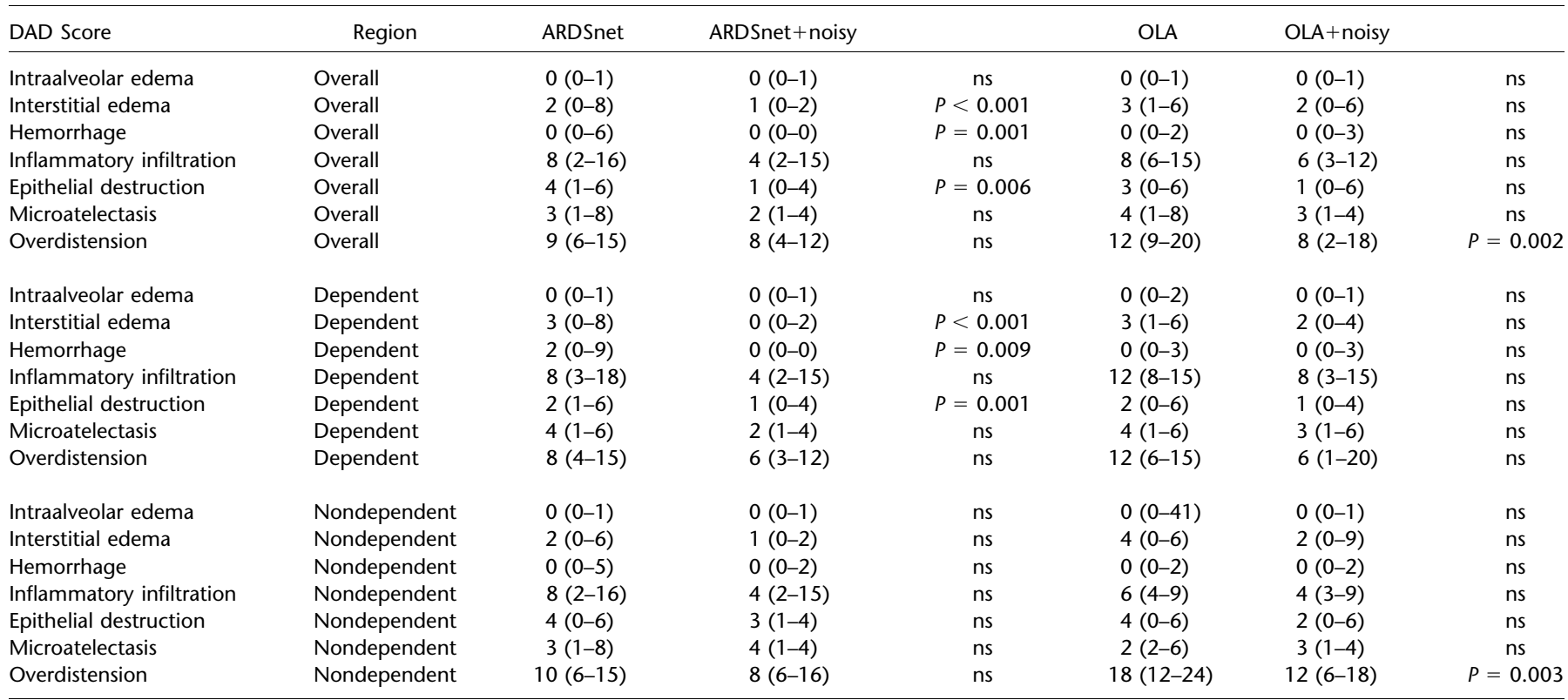

Definition of abbreviations: ARDSnet = ventilation according to the ARDS Network protocol; dependent = gravitational dependent lung regions (dorsal); noisy =

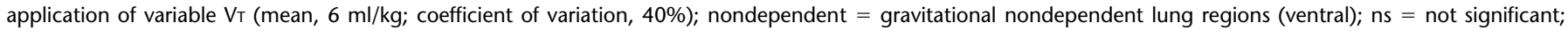
OLA = ventilation according to the open lung approach;

* Values are given as median and interquartile range. Statistical tests were performed using the Mann-Whitney $U$ test and adjusted for multiple measurements by means of the Bonferroni procedure.

directly assess regional lung aeration, although the improvement in functional parameters and redistribution of PBF suggests recruitment with noisy ventilation. Third, the short observational period of 6 hours does not allow extrapolation of our results to long-term mechanical ventilation. Fourth, it can be argued that other combinations of lower PEEP and $\mathrm{FI}_{\mathrm{O}_{2}}$ would probably lead to different results. However, the use of lower PEEP would have resulted in worse respiratory function and possibly increased injury due to cyclic alveolar collapse/ reopening. On the other hand, higher PEEP does not match the recommendations of the ARDSnet and would have likely resulted in increased overdistension, as observed in the OLA group. Fifth, we used only one distribution of VT and did not vary f. Thus, we cannot exclude that other $V_{T}$ distribution patterns and/or f variation would lead to different results.
However, our findings show that variation of $\mathrm{V}_{\mathrm{T}}$ alone is enough to achieve beneficial effects.

\section{Conclusion}

In a surfactant depletion model of ALI, the use of random variable $\mathrm{V}_{\mathrm{T}}$ improves respiratory function and reduces histological damage during mechanical ventilation according to the ARDSnet protocol and OLA without increasing lung inflammation and mechanical stress.

Conflict of Interest Statement: P.M.S. has been granted a patent (15\%) on an assisted mode of ventilation that is based on variability of pressure support. He can benefit indirectly from variable controlled ventilation. A.R.C. does not have a financial relationship with a commercial entity that has an interest in the subject of this manuscript. P.P. does not have a financial relationship with a commercial entity that has an interest in the subject of this manuscript. C.H. does not have

TABLE 5. CELLULAR MARKERS OF INFLAMMATION AND MECHANICAL STRESS (ARBITRARY UNITS)*

\begin{tabular}{|c|c|c|c|c|c|c|}
\hline Ventilation Mode & Region & AREG & TNC & IL-6 & IL-8 & TGF- $\beta$ \\
\hline ARDSnet & Overall & $0.6(0.4-2.0)$ & $0.3(0.2-1.6)$ & $0.5(0.1-1.5)$ & $0.7(0.3-1.0)$ & $1.0(0.6-1.4)$ \\
\hline ARDSnet+noisy & Overall & $0.7(0.26-1.1)$ & $0.7(0.2-0.8)$ & $0.7(0.1-3.1)$ & $0.7(0.2-1.3)$ & $0.8(0.6-0.9)$ \\
\hline OLA & Overall & $0.6(0.3-0.9)$ & $0.7(0.3-1.3)$ & $0.6(0.2-1.0)$ & $0.8(0.3-1.8)$ & $0.8(0.6-1.2)$ \\
\hline OLA+noisy & Overall & $0.4(0.2-1.0)$ & $0.5(0.2-1.7)$ & $0.5(0.1-1.0)$ & $0.6(0.1-1.1)$ & $0.9(0.6-1.0)$ \\
\hline ARDSnet & Dependent & $0.7(0.1-2.2)$ & $0.3(0.0-3.0)$ & $0.1(0.0-2.7)$ & $0.3(0.0-2.8)$ & $1.1(0.3-1.4)$ \\
\hline ARDSnet+noisy & Dependent & $0.4(0.2-0.7)$ & $0.3(0.5-1.1)$ & $0.1(0.0-1.7)$ & $0.2(0.1-0.5)$ & $0.7(0.5-1.0)$ \\
\hline OLA & Dependent & $0.6(0.2-0.9)$ & $0.3(0.1-0.6)$ & $0.2(0.1-0.7)$ & $0.3(0.2-1.1)$ & $0.7(0.6-0.8)$ \\
\hline OLA+noisy & Dependent & $0.2(0.1-10)$ & $0.2(0.2-0.5)$ & $0.1(0.0-1.6)$ & $0.1(0.1-2.6)$ & $0.7(0.6-0.8)$ \\
\hline ARDSnet & Nondependent & $0.5(0.4-2.0)$ & $0.7(0.2-1.6)$ & $0.6(0.4-1.5)$ & $0.9(0.6-1.0)$ & $0.8(0.6-1.5)$ \\
\hline ARDSnet+noisy & Nondependent & $1.1(0.7-2.0)$ & $0.7(0.5-1.1)$ & $1.8(0.7-5.1)$ & $1.3(0.7-1.8)$ & $0.8(0.8-0.9)$ \\
\hline OLA & Nondependent & $0.6(0.3-0.9)$ & $1.3(0.7-1.8)$ & $0.9(0.5-3.9)$ & $1.3(0.7-1.8)$ & $1.1(0.8-1.3)$ \\
\hline OLA+noisy & Nondependent & $0.5(0.3-2.3)$ & $1.2(0.6-2.0)$ & $0.7(0.5-1.0)$ & $0.8(0.7-1.1)$ & $1.0(1.0-1.3)$ \\
\hline
\end{tabular}

Definition of abbreviations: ARDSnet = ventilation according to the ARDS Network protocol; AREG = amphiregulin; dependent = gravitational dependent lung regions

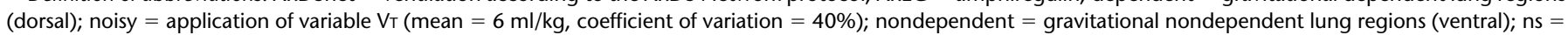
not significant; OLA = ventilation according to the open lung approach; TGF- $\beta=$ transforming growth factor- $\beta$; TNC = tenascin-c.

* Values are given as median and interquartile range. Statistical tests were performed using the Mann-Whitney U-test and adjusted for multiple measurements by means of the Bonferroni procedure. 
a financial relationship with a commercial entity that has an interest in the subject of this manuscript. C.M. does not have a financial relationship with a commercial entity that has an interest in the subject of this manuscript. M.K. does not have a financial relationship with a commercial entity that has an interest in the subject of this manuscript. M.H. does not have a financial relationship with a commercial entity that has an interest in the subject of this manuscript. M.v.N. does not have a financial relationship with a commercial entity that has an interest in the subject of this manuscript. C.D. does not have a financial relationship with a commercial entity that has an interest in the subject of this manuscript. M.B. does not have a financial relationship with a commercial entity that has an interest in the subject of this manuscript. S.U. does not have a financial relationship with a commercial entity that has an interest in the subject of this manuscript. T.K. has been granted a patent $(10 \%)$ on an assisted mode of ventilation that is based on variability of pressure support. She can benefit indirectly from variable controlled ventilation. M.G.d.A. has been granted a patent (75\%) on an assisted mode of ventilation that is based on variability of pressure support. He can benefit indirectly from variable controlled ventilation.

Acknowledgment: The authors thank Dr. Bärbel Wiedemann from the Institute of Informatics and Biometry, TU Dresden, Germany, for statistical analysis; Mr. Thomas Handzsuj from Dräger Medical AG, Lübeck, and Prof. Dr. Edmund Koch and Dr. Alexander Krüger from the Clinical Sensoring and Monitoring Group, Clinic of Anesthesiology and Intensive Care Medicine, University Clinic Carl Gustav Carus, TU Dresden, for assistance with the controller of the mechanical ventilator; and Dr. Lilla Knels and the staff of the Institute of Anatomy, who helped with histological tissue processing.

\section{References}

1. Amato MB, Barbas CS, Medeiros DM, Magaldi RB, Schettino GP, Lorenzi-Filho G, Kairalla RA, Deheinzelin D, Munoz C, Oliveira R, et al. Effect of a protective-ventilation strategy on mortality in the acute respiratory distress syndrome. N Engl J Med 1998;338:347-354.

2. The Acute Respiratory Distress Syndrome Network. Ventilation with lower tidal volumes as compared with traditional tidal volumes for acute lung injury and the acute respiratory distress syndrome. $N$ Engl J Med 2000;342:1301-1308.

3. Brower RG, Lanken PN, MacIntyre N, Matthay MA, Morris A, Ancukiewicz M, Schoenfeld D, Thompson BT. Higher versus lower positive end-expiratory pressures in patients with the acute respiratory distress syndrome. $N$ Engl J Med 2004;351:327-336.

4. Lachmann B. Open up the lung and keep the lung open. Intensive Care Med 1992;18:319-321.

5. Amato MB, Barbas CS, Medeiros DM, Schettino GP, Lorenzi FG, Kairalla RA, Deheinzelin D, Morais C, Fernandes EO, Takagaki TY. Beneficial effects of the "open lung approach" with low distending pressures in acute respiratory distress syndrome: a prospective randomized study on mechanical ventilation. Am J Respir Crit Care Med 1995;152:1835-1846.

6. Tobin MJ, Mador MJ, Guenther SM, Lodato RF, Sackner MA. Variability of resting respiratory drive and timing in healthy subjects. J Appl Physiol 1988;65:309-317.

7. Suki B, Alencar AM, Sujeer MK, Lutchen KR, Collins JJ, Andrade JS $\mathrm{Jr}$, Ingenito EP, Zapperi S, Stanley HE. Life-support system benefits from noise. Nature 1998;393:127-128.

8. Arold SP, Mora R, Lutchen KR, Ingenito EP, Suki B. Variable tidal volume ventilation improves lung mechanics and gas exchange in a rodent model of acute lung injury. Am J Respir Crit Care Med 2002; 165:366-371.

9. Bellardine CL, Hoffman AM, Tsai L, Ingenito EP, Arold SP, Lutchen KR, Suki B. Comparison of variable and conventional ventilation in a sheep saline lavage lung injury model. Crit Care Med 2006;34:439-445.

10. McMullen MC, Girling LG, Graham MR, Mutch WA. Biologically variable ventilation improves oxygenation and respiratory mechanics during one-lung ventilation. Anesthesiology 2006;105:91-97.

11. Mutch WA, Harms S, Ruth GM, Kowalski SE, Girling LG, Lefevre GR. Biologically variable or naturally noisy mechanical ventilation recruits atelectatic lung. Am J Respir Crit Care Med 2000;162:319-323.

12. Boker A, Haberman CJ, Girling L, Guzman RP, Louridas G, Tanner JR, Cheang M, Maycher BW, Bell DD, Doak GJ. Variable ventilation improves perioperative lung function in patients undergoing abdominal aortic aneurysmectomy. Anesthesiology 2004;100:608-616.

13. Boker A, Graham MR, Walley KR, McManus BM, Girling LG, Walker E, Lefevre GR, Mutch WA. Improved arterial oxygenation with biologically variable or fractal ventilation using low tidal volumes in a porcine model of acute respiratory distress syndrome. Am J Respir Crit Care Med 2002;165:456-462.

14. Nam AJ, Brower RG, Fessler HE, Simon BA. Biologic variability in mechanical ventilation rate and tidal volume does not improve oxygenation or lung mechanics in canine oleic acid lung injury. $\mathrm{Am}$ J Respir Crit Care Med 2000;161:1797-1804.

15. Brewster JF, Graham MR, Mutch WA. Convexity, Jensen's inequality and benefits of noisy mechanical ventilation. J R Soc Interface 2005;2: 393-396.

16. Gama de Abreu M, Spieth PM, Höhn C, Meißner C, Canani K, Knels L, Kasper M, Koch T. Chaotic variation of tidal volume improves different protective mechanical ventilation strategies [abstract]. $\mathrm{Am}$ J Respir Crit Care Med 2007;175:A788.

17. Lachmann B, Robertson B, Vogel J. In vivo lung lavage as an experimental model of the respiratory distress syndrome. Acta Anaesthesiol Scand 1980;24:231-236.

18. Gama de Abreu M, Quelhas AD, Spieth P, Brauer G, Knels L, Kasper M, Pino AV, Bleyl JU, Hubler M, Bozza F, et al. Comparative effects of vaporized perfluorohexane and partial liquid ventilation in oleic acid- induced lung injury. Anesthesiology 2006;104:278-289.

19. Spieth PM, Carvalho AR, Güldner A, Pelosi P, Kirichuk O, Koch T, Gama de Abreu M. Effects of different levels of pressure support variability in experimental lung injury. Anesthesiology 2009;110:214215.

20. Hubler M, Souders JE, Shade ED, Hlastala MP, Polissar NL, Glenny RW. Validation of fluorescent-labeled microspheres for measurement of relative blood flow in severely injured lungs. J Appl Physiol 1999; 87:2381-2385.

21. Spieth PM, Knels L, Kasper M, Domingues QA, Wiedemann B, Lupp A, Hubler M, Gianella NA, Koch T, Gama de Abreu M. Effects of vaporized perfluorohexane and partial liquid ventilation on regional distribution of alveolar damage in experimental lung injury. Intensive Care Med 2007;33:308-314.

22. Lefevre GR, Kowalski SE, Girling LG, Thiessen DB, Mutch WA. Improved arterial oxygenation after oleic acid lung injury in the pig using a computer-controlled mechanical ventilator. Am J Respir Crit Care Med 1996;154:1567-1572.

23. Funk DJ, Graham MR, Girling LG, Thliveris JA, McManus BM, Walker EK, Rector ES, Hillier C, Scott JE, Mutch WA. A comparison of biologically variable ventilation to recruitment manoeuvres in a porcine model of acute lung injury. Respir Res 2004;5:22.

24. Rosenthal C, Caronia C, Quinn C, Lugo N, Sagy M. A comparison among animal models of acute lung injury. Crit Care Med 1998;26:912-916.

25. Gama de Abreu M, Spieth PM, Pelosi P, Carvalho AR, Walter C, Schreiber-Ferstl A, Aikele P, Neykova B, Hübler M, Koch T. Noisy pressure support ventilation: a pilot study on a new assisted ventilation mode in experimental lung injury. Crit Care Med 2008;36:818-827.

26. Arold SP, Suki B, Alencar AM, Lutchen KR, Ingenito EP. Variable ventilation induces endogenous surfactant release in normal guinea pigs. Am J Physiol Lung Cell Mol Physiol 2003;285:L370-L375.

27. Mutch WA, Graham MR, Girling LG, Brewster JF. Fractal ventilation enhances respiratory sinus arrhythmia. Respir Res 2005;6:41.

28. Luecke T, Meinhardt JP, Herrmann P, Weiss A, Quintel M, Pelosi P. Oleic acid vs saline solution lung lavage-induced acute lung injury: effects on lung morphology, pressure-volume relationships, and response to positive end-expiratory pressure. Chest 2006;130:392-401.

29. Suarez-Sipmann F, Bohm SH, Tusman G, Pesch T, Thamm O, Reissmann H, Reske A, Magnusson A, Hedenstierna G. Use of dynamic compliance for open lung positive end-expiratory pressure titration in an experimental study. Crit Care Med 2007;35:214-221.

30. Karmrodt J, Bletz C, Yuan S, David M, Heussel CP, Markstaller K. Quantification of atelectatic lung volumes in two different porcine models of ARDS. B J Anaesth 2006;97:883-895.

31. Dreyfuss D, Saumon G. Ventilator-induced lung injury: lessons from experimental studies. Am J Respir Crit Care Med 1998;157:294-323.

32. Uhlig S, Uhlig U. Pharmacological interventions in ventilator-induced lung injury. Trends Pharmacol Sci 2004;25:592-600.

33. Pelosi P, Rocco PR. Effects of mechanical ventilation on the extracellular matrix. Intensive Care Med 2008:34:631-639.

34. Bilek AM, Dee KC, Gaver DP III. Mechanisms of surface-tensioninduced epithelial cell damage in a model of pulmonary airway reopening. J Appl Physiol 2003;94:770-783.

35. Dolinay T, Kaminski N, Felgendreher M, Kim HP, Reynolds P, Watkins SC, Karp D, Uhlig S, Choi AM. Gene expression profiling of target genes in ventilator-induced lung injury. Physiol Genomics 2006;26:6875.

36. Thammanomai A, Majumdar A, Bartolak-Suki E, Suki B. Effects of reduced tidal volume ventilation on pulmonary function in mice before and after acute lung injury. J Appl Physiol 2007;103:15511559 . 